\title{
Microwave-Assisted Simultaneous Extraction of Luteolin and Apigenin from Tree Peony Pod and Evaluation of Its Antioxidant Activity
}

\author{
Hongzheng Wang, ${ }^{1,2}$ Lei Yang, ${ }^{1,2}$ Yuangang $\mathrm{Zu},{ }^{1,2}$ and Xiuhua Zhao ${ }^{1,2}$ \\ ${ }^{1}$ Key Laboratory of Forest Plant Ecology, Ministry of Education, Northeast Forestry University, Box 332, Hexing Road 26, \\ Harbin, Heilongjiang 150040, China \\ ${ }^{2}$ State Engineering Laboratory for Bioresource Eco-Utilization, Northeast Forestry University, Harbin 150040, China
}

Correspondence should be addressed to Lei Yang; nefuyanglei@163.com

Received 28 April 2014; Accepted 29 August 2014; Published 22 October 2014

Academic Editor: Fred Stevens

Copyright (C) 2014 Hongzheng Wang et al. This is an open access article distributed under the Creative Commons Attribution License, which permits unrestricted use, distribution, and reproduction in any medium, provided the original work is properly cited.

An efficient microwave-assisted extraction (MAE) technique was employed in simultaneous extraction of luteolin and apigenin from tree peony pod. The MAE procedure was optimized using response surface methodology (RSM) and compared with other conventional extraction techniques of macerate extraction (ME) and heat reflux extraction (HRE). The optimal conditions of MAE were as follows: employing $70 \%$ ethanol volume fraction as solvent, soaking time of $4 \mathrm{~h}$, liquid-solid ratio of 10 (mL/g), microwave irradiation power of $265 \mathrm{~W}$, microwave irradiation time of $9.6 \mathrm{~min}$, and 3 extraction cycles. Under the optimal conditions, $151 \mu \mathrm{g} / \mathrm{g}$ luteolin and $104 \mu \mathrm{g} / \mathrm{g}$ apigenin were extracted from the tree peony pod. Compared with ME and HRE, MAE gave the highest extraction efficiency. The antioxidant activities of the extracts obtained by MAE, ME, and HRE were evaluated using a 2,2-di(4tert-octylphenyl)-1-picrylhydrazyl (DPPH) free radical-scavenging assay, a ferric reducing antioxidant power assay (FRAP), and a reducing power assay. Meanwhile, the structural changes of the unprocessed and processed tree peony pod samples were analyzed by scanning electron microscopy.

\section{Introduction}

Tree peony was loved as an ornamental for its beautiful flower. During its cultivation for thousands of years, many cultivars of tree peony have been bred. Root cortex of tree peony is also used as an important traditional Chinese medicine (TCM), having been recorded in the Pharmacopoeia of the People's Republic of China [1], which is beneficial for the treatment of diseases related mainly to irregular menstruation and dysmenorrhea [2]. Peony seed oil is rich in $\alpha$-linolenic acid [3], which has beneficial effects on human nutrition and health. The seed oils of Fengdan (Paeonia ostii) and Ziban (Paeonia rockii) have been approved as new resource food by government of China in 2011. The market demand for peony tree seed oil is growing with the enhancing cognition of its nutrition functions. The remaining pod is around $60 \%$ of the total bulk, and it has been either disposed of as landfill waste or used as low-value fuel. A growing attention to the comprehensive utilization of tree peony resource is paid by people. The pod of tree peony contains valuable bioflavonoids. Among the flavonoids, luteolin and apigenin are the main flavones with better pharmacological activities [4].

Flavonoids are a group of benzo- $\gamma$-pyran derivatives, comprising a very large class of low molecular weight polyphenol compounds. Among the flavonoids, luteolin $\left(3^{\prime}, 4^{\prime}, 5,7\right.$-tetrahydroxyflavone $)$ and apigenin (4',5,7,trihydroxyflavone) (Figure 1) are reportedly important functional components, which exhibit the pharmacological effects. For example, luteolin has been found to possess antioxidant [5], anticancer action [6], anti-inflammatory [7], antihepatotoxic action [8], antiallergic, antiosteoporotic [9], antidiabetic [10], and antiplatelet and vasodilatory activity [11]. In addition to antioxidant, anticancer, and 


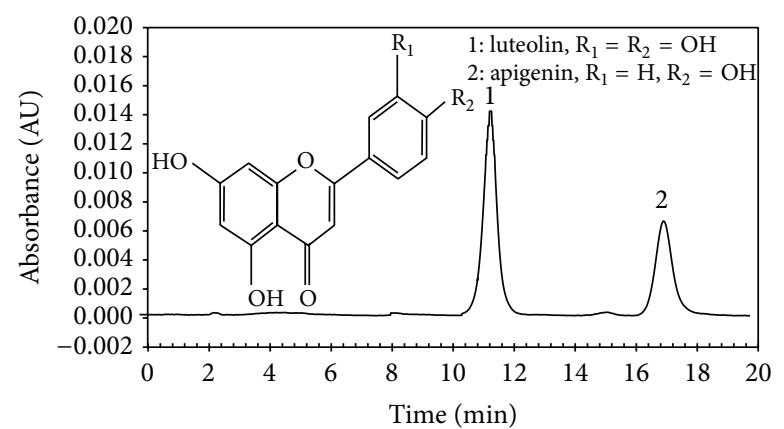

(a)

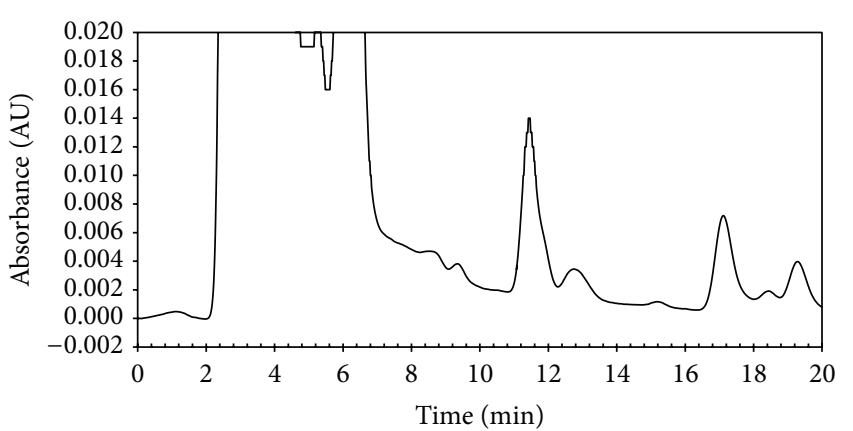

(b)

FIGURE 1: The HPLC profiles of a mixture of standards of luteolin and apigenin (a) and the two compounds in an extract obtained by MAE using $70 \%$ ethanol as extraction solvent (b).

anti-inflammatory, apigenin also exhibits antihyperglycemic action [12] and antinociceptive effect [13]. Luteolin and apigenin are natural food additives used extensively in the food and pharmaceutical industries. Flavonoids constitute a large part of global nutraceuticals market [14] and the current nutraceuticals market was estimated at $\$ 151$ billion in 2011 and was growing by about $6.5 \%$ per annum [15]. The pod of tree peony, after flavonoids extraction, could still be used as a high-polysaccharide stock feed in dry form, increasing the potential return for the seed oil industry and reducing the pollution load on the environment.

As far as we know, luteolin and apigenin can be obtained from plant materials, such as Sesbania grandifolra [16], Cajanus cajan [17], Apium graveolens [18], Platycodon grandiflorum [19], Mentha spicata [20], and Perilla frutescens [21]. A new source of luteolin and apigenin would be provided if an efficient extraction technology of luteolin and apigenin from tree peony pod was developed. Meanwhile, it also could be an economical utilization of the disused pod.

Many methods have been developed for separation of luteolin or apigenin from plant materials, such as maceration extraction (ME) [19], Soxhlet extraction [20], and heat reflux extraction (HRE) [21]. However, these extraction techniques are inefficient, time-consuming, and energy-consuming [22]. In recent years, the development and use of environmentally friendly methods have become increasingly popular. Microwave-assisted extraction (MAE) is an extraction technique that offers high reproducibility, short extraction time, simple manipulation, and low solvent consumption, temperature, and energy input [23-26]. MAE utilizes the energy of microwaves to cause dipole rotation of molecules. In the process of MAE, the solvent is rapidly heating and the cell wall of the plant material is quickly destroyed, accelerating the dissolution and extraction of components.

In this paper, the objective is to develop an effective and environment-friendly microwave-assisted approach for the extraction of luteolin and apigenin from the tree peony pod. The influences of the conditions on yields of the luteolin and apigenin were optimized using response surface methodology (RSM). Moreover, the antioxidant activities of the extracts, luteolin, and apigenin were evaluated by DPPH, FRAP, and reducing power assays. Furthermore, the microstructure changes of tree peony pod samples before and after extraction were characterized by scanning electron microscopy (SEM). The present study offers an alternative method for the highly effective utilization of a side product of tree peony utilization.

\section{Experimental}

2.1. Plant Materials and Chemicals. Fresh ripe fruits of the cultivated tree peony (Paeonia ostii) were hand-harvested in September from Heze (Shandong, China). The pod was separated, cleaned, and dried in oven at $45^{\circ} \mathrm{C}$. The dried sample was pulverized using plant grinder (FZ102, Taisite, Tianjin, China) and then sieved (80-120 mesh) before use. Apigenin ( $\geq 95 \%)$, luteolin $(\geq 97 \%)$, gallic acid $(\geq 97.5 \%)$, rutin $(\geq 94 \%)$, Folin-Ciocalteu reagent, 2,2-di(4tert-octylphenyl)-1-picrylhydrazyl (DPPH, 95\%), 6-hydroxy2,5,7,8-tetramethylchroman-2-carboxylic acid (Trolox, 97\%), and 2,4,6-tris(2-pyridyl)-s-triazine (TPTZ, $\geq 98 \%$ ) were purchased from Sigma-Aldrich Co. LLC (St. Louis, MO, USA). Ethanol, sodium nitrite $\left(\mathrm{NaNO}_{2}\right)$, aluminum trichloride $\left(\mathrm{AlCl}_{3}\right)$ and sodium hydroxide $(\mathrm{NaOH})$, sodium carbonate $\left(\mathrm{Na}_{2} \mathrm{CO}_{3}\right)$, acetic acid, hydrochloric acid ( $\left.\mathrm{HCl}\right)$, ferric chloride $\left(\mathrm{FeCl}_{3}\right)$, sodium dihydrogen phosphate $\left(\mathrm{NaH}_{2} \mathrm{PO}_{4}\right)$, disodium hydrogen phosphate $\left(\mathrm{Na}_{2} \mathrm{HPO}_{4}\right)$, potassium ferricyanide, and trichloroacetic acid (TCA) were purchased from Sinopharm Chemical Reagent Co., Ltd. (Beijing, China). Methanol of chromatographic grade (99.9\%) was purchased from J\&K Scientific Ltd. (Beijing, China). All solvents and chemicals except methanol were of analytical grade. Reverse osmosis Milli-Q water (Millipore, Bedford, MA, USA) was used for all solutions and dilutions. All of the solvents prepared were filtered through $0.45 \mu \mathrm{m}$ microporous membrane (Guangfu, Tianjin, China).

2.2. Apparatus. The experimental setup of the microwave extraction apparatus was from Wang et al. [23] and Liu et al. [24]. Briefly, a domestic WP700 microwave-assisted extraction unit (Glanz, Guangdong, China) with a $2450 \mathrm{MHz}$ magnetron and power continuously adjustable was used in the extraction step. The dimensions of the interior cavity of 
TABLE 1: Experimental design matrix to screen important variables for total extraction yield of luteolin and apigenin.

\begin{tabular}{|c|c|c|c|c|}
\hline Run & $\begin{array}{c}\text { Factor A } \\
\text { Liquid-solid ratio }(\mathrm{mL} / \mathrm{g})\end{array}$ & $\begin{array}{c}\text { Factor B } \\
\text { Microwave irradiation } \\
\text { power }(\mathrm{W})\end{array}$ & $\begin{array}{c}\text { Factor C } \\
\text { Microwave irradiation time } \\
(\mathrm{min})\end{array}$ & $\begin{array}{c}\text { Response } \\
\text { Total extraction yield } \\
(\mu \mathrm{g} / \mathrm{g})\end{array}$ \\
\hline 1 & 8 & 230 & 8 & 228 \\
\hline 2 & 8 & 120 & 10 & 163 \\
\hline 3 & 8 & 230 & 8 & 231 \\
\hline 4 & 8 & 120 & 6 & 150 \\
\hline 5 & 6 & 230 & 6 & 179 \\
\hline 6 & 6 & 120 & 8 & 117 \\
\hline 7 & 10 & 120 & 8 & 175 \\
\hline 8 & 10 & 230 & 10 & 251 \\
\hline 9 & 6 & 230 & 10 & 187 \\
\hline 10 & 8 & 230 & 8 & 231 \\
\hline 11 & 8 & 385 & 10 & 182 \\
\hline 12 & 8 & 230 & 8 & 230 \\
\hline 13 & 8 & 385 & 6 & 175 \\
\hline 14 & 10 & 230 & 6 & 239 \\
\hline 15 & 8 & 230 & 8 & 230 \\
\hline 16 & 6 & 385 & 8 & 138 \\
\hline 17 & 10 & 385 & 8 & 204 \\
\hline
\end{tabular}

TABLE 2: Comparison of MAE with other extraction methods, mean \pm S.D $(n=3)$.

\begin{tabular}{|c|c|c|c|c|c|c|c|}
\hline \multirow{2}{*}{ Number } & \multirow{2}{*}{$\begin{array}{l}\text { Extraction } \\
\text { method }\end{array}$} & \multicolumn{2}{|r|}{ Extraction time $(\mathrm{h})$} & \multirow{2}{*}{ Solvent consumption $(\mathrm{mL} / \mathrm{g})$} & \multicolumn{3}{|c|}{ Extraction yield $\pm \mathrm{SD}(\mu \mathrm{g} / \mathrm{g})$} \\
\hline & & Soak time (h) & Energy consumption time (min) & & Luteolin & Apigenin & Total \\
\hline 1 & $\mathrm{ME}$ & 36 & 0 & 30 & $82 \pm 4^{\mathrm{a}}$ & $63 \pm 3^{\mathrm{a}}$ & 145 \\
\hline 2 & HRE & 0 & 120 & 30 & $131 \pm 6^{b}$ & $89 \pm 4^{\mathrm{b}}$ & 220 \\
\hline 3 & MAE & 2 & 24 & 30 & $151 \pm 7^{\mathrm{c}}$ & $104 \pm 4^{\mathrm{c}}$ & 255 \\
\hline
\end{tabular}

${ }^{a}$ Values followed by the same letter in the same assay are not significantly different $(P>0.05)$.

the oven are $215 \mathrm{~mm} \times 350 \mathrm{~mm} \times 330 \mathrm{~mm}$. It was modified in our laboratory with the addition of a water condenser whose wall was coated with polytetrafluoroethylene to prevent the leakage of microwaves. A round-bottom flask with a capacity of $100 \mathrm{~mL}$ was placed in the oven and connected to a reflux condenser. The whole system was run at atmospheric pressure and could be employed at the maximum power of $700 \mathrm{~W}$.

2.3. MAE Procedure. $1.00 \mathrm{~g}$ of the ground dried pod sample was mixed with ethanol solution in a $100 \mathrm{~mL}$ round bottom flask. Soaked for a certain time, then the suspension was extracted by MAE. The optimum ethanol volume fraction, soaking time, liquid-solid ratio, microwave irradiation power, microwave irradiation time, and number of extraction cycles were systematically studied in this work. After MAE, it was cooled to room temperature rapidly by a cold bath and centrifuged with $10,000 \times \mathrm{g}$ for 10 minutes. The supernatant was collected for subsequent HPLC analysis.

2.4. Optimization MAE by Response Surface Method (RSM). In order to highlight the most influential factors and possible interactions, the operating conditions were optimized by
RSM using the Box-Behnken software in data processing. Box-Behnken design was applied using Design-Expert 8.06 without any blocking. The bounds of the factors were 610 ratio of liquid-solid, $120-385 \mathrm{~W}$ of microwave irradiation power, and 6-10 minutes of microwave irradiation time. The specific protocols for the experiments were shown in Table 1.

2.5. Traditional Reference Extraction Procedure. The ME and HRE experiments were operated under the optimized conditions. $1.00 \mathrm{~g}$ of the ground dried pod sample was mixed with $10 \mathrm{~mL} 70 \%$ volume fraction of ethanol in a $100 \mathrm{~mL}$ round bottom flask. The main technical parameters used were listed in Table 2. After completion of extraction, the liquid retentate was decanted and filtered through Whatman number 2 filter paper (Whatman International Limited, Kent, England). The filtrate was concentrated in a vacuum evaporator (R206, Senco Technology Co. Ltd., Shanghai, China) at $60^{\circ} \mathrm{C}$ and then lyophilized in a freeze-dryer (Scientz-10N, Ningbo Scientz Biotechnology Co., Ltd, China) to obtain crude extract. The cold trap temperature was $-56^{\circ} \mathrm{C}$ and the vacuum was less than $1 \mathrm{~Pa}$. The crude extract was collected and stored in $4^{\circ} \mathrm{C}$ until it was used. 
2.6. HPLC Analysis and Quantification. The HPLC system consisted of a Waters 1525 Binary HPLC Pump, 2489 UV/Visible Detector, and automatic column temperature control box. Chromatographic separation was performed on Aichrom Bond-AQ C18 reversed-phase column $(4.6 \mathrm{~mm} \times$ $250 \mathrm{~mm}, 5 \mu \mathrm{m}$, Abel Industries, Canada).

For HPLC analysis, the mobile phase was methanolwater-phosphate acid $(30: 69.3: 0.7, \mathrm{v} / \mathrm{v} / \mathrm{v})$, and the flow rate was $1 \mathrm{~mL} / \mathrm{min}$. The column temperature was maintained at $25^{\circ} \mathrm{C}$. The wavelength used for luteolin and apigenin was $360 \mathrm{~nm} .10 \mu \mathrm{L}$ example was injected and the run time was $20 \mathrm{~min}$. The retention times for luteolin and apigenin were 11.4 and $17.1 \mathrm{~min}$ (Figure 1), respectively. Under these conditions, the two flavonoids were baseline separated. Luteolin and apigenin were identified by comparing their retention time with corresponding peaks in the standard solution.

Corresponding calibration curves for luteolin and apigenin were $Y_{\text {luteolin }}=63937 X+37891\left(R^{2}=0.9999\right)$ and $Y_{\text {apigenin }}=73716 X+24357\left(R^{2}=0.9998\right)$. A good linearity was found for each of luteolin and apigenin in the range of $1-150$ and $0.67-85 \mu \mathrm{g} / \mathrm{mL}$, respectively.

2.7. Determination of Total Flavonoids. The total flavonoids contents of crude extracts obtained by MAE, ME, and HRE were determined by the method of Guo et al. [27] with some modifications. Sample $(0.16 \mathrm{mg} / \mathrm{mL} ; 2.5 \mathrm{~mL})$ was mixed with

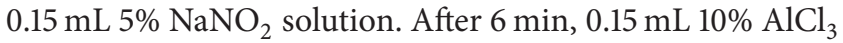
was added. After another $6 \mathrm{~min}, 2 \mathrm{~mL} 4 \% \mathrm{NaOH}$ was added. The absorbance was measured at $510 \mathrm{~nm}$ using a UV-Vis spectrophotometer (Shimadzu UV-2550; Shimadzu, Kyoto, Japan) after incubation for $15 \mathrm{~min}$. The determination was performed in triplicate. Quantification was done on the basis of the standard curve of rutin.

2.8. Determination of Total Phenolics. The total phenolics contents of crude extracts obtained by MAE, ME, and HRE were determined by Folin-Ciocalteu method [28] with little modifications. Briefly, $0.5 \mathrm{~mL}$ sample $(0.12 \mathrm{mg} / \mathrm{mL})$ was mixed with $2.8 \mathrm{~mL} \mathrm{H}_{2} \mathrm{O}$ and $0.5 \mathrm{~mL}$ Folin-Ciocalteu reagent. After $3 \mathrm{~min}, 1.5 \mathrm{~mL} 7.5 \% \mathrm{Na}_{2} \mathrm{CO}_{3}$ was added. The reaction mixture was mixed thoroughly and incubated at $40^{\circ} \mathrm{C}$ for $30 \mathrm{~min}$ in the dark. Absorbance was then measured at $765 \mathrm{~nm}$ using the spectrophotometer (UV-2550, Shimadzu, Japan). Gallic acid was used to calculate the standard curve (0.06$0.3 \mathrm{mg} / \mathrm{mL}$ ). The determination was performed in triplicate.

2.9. Evaluation of Antioxidant Capacity. To evaluate antioxidant capacities of crude extracts obtained by MAE, ME, and HRE, their DPPH radical-scavenging activity, FRAR, and reducing power were determined, with standard compounds of luteolin and apigenin as the positive controls.

DPPH radical-scavenging activity was measured according to the method of $\mathrm{Zu}$ et al. [29] with a slight modification. $0.1 \mathrm{~mL}$ of each sample at different concentration (0.25$1.6 \mathrm{mg} / \mathrm{mL}$ in $70 \%$ ethanol) was added to $3.9 \mathrm{~mL} 25 \mathrm{mg} / \mathrm{mL}$ DPPH solution in $95 \%$ ethanol. The mixture was mixed vigorously and allowed to stand at room temperature in the dark for $30 \mathrm{~min}$. Then the absorbance was measured at
$517 \mathrm{~nm}$, with absolute ethanol as the control, and the DPPH radical-scavenging activity was calculated.

FRAP was assayed according to Liu et al. method [30]. Briefly, a working solution was prepared freshly by mixing $250 \mathrm{~mL}$ sodium acetate buffer $(\mathrm{pH} 3.6,300 \mathrm{mM}), 25 \mathrm{~mL}$ TPTZ solution (10 mM, in $40 \mathrm{mM} \mathrm{HCl})$, and $25 \mathrm{~mL} 20 \mathrm{mM}$ $\mathrm{FeCl}_{3}$ solution. The mixture was incubated at $37^{\circ} \mathrm{C}$ for $30 \mathrm{~min}$ and was referred to as FRAP solution. $0.15 \mathrm{~mL}$ of each sample at different concentration $(0.05-0.25 \mathrm{mg} / \mathrm{mL}$ in $70 \%$ ethanol) was mixed with $2.85 \mathrm{~mL}$ FRAP solution and allowed standing in the dark for $30 \mathrm{~min}$. Then the absorbance at $593 \mathrm{~nm}$ was measured. A standard curve was prepared using Trolox ranging from 37.5 to $600 \mu \mathrm{M}$. The FRAP was expressed as $\mu$ mol Trolox equivalents (TE)/g crude or positive control.

Reducing power assay was following the method of $\mathrm{Zu}$ et al. [29]. $0.5 \mathrm{~mL}$ of each sample at different concentration $(0.015-0.25 \mathrm{mg} / \mathrm{mL}$ in $70 \%$ ethanol) was mixed with $1.5 \mathrm{~mL}$ sodium phosphate buffer ( $\mathrm{pH} 6.6,0.2 \mathrm{M}$ ) and $1.5 \mathrm{~mL} 1 \%$ potassium ferricyanide solution. The mixture was incubated in a water bath at $50^{\circ} \mathrm{C}$ for $20 \mathrm{~min}$. Then, $1.5 \mathrm{~mL} 10 \%$ trichloroacetic acid (TCA) solution and $3 \mathrm{~mL}$ water was added. The mixture was mixed vigorously and the absorbance was measured at $707 \mathrm{~nm}$. Increased absorbance of the mixture indicated greater reducing power.

2.10. SEM Observation. In order to investigate the effects of MAE, ME, and HRE on morphological alterations of the pod material, the pod material and residues of MAE, ME, and HRE were scanned with a SEM system (Quanta-200, FEI Company, USA). Samples were fixed on a specimen holder with aluminium tape and then sputtered with the gold and examined under high vacuum condition at an accelerating voltage of $10 \mathrm{kV}(20 \mu \mathrm{m}, 1000 \mathrm{x}$ magnification).

2.11. Statistical Analysis. Statistical analyses were performed with SPSS Statistics (Version 19, IBM Company, USA). All experimental results were the average of three parallel measurements expressed as the mean \pm standard deviation (SD). The Fisher test value ( $F$-value) was obtained from the ANOVA test generated by the software. $P$ values $<0.05$ were regarded as significant.

\section{Results and Discussion}

3.1. Optimization of Luteolin and Apigenin Extraction Using a Factorial Design. The univariate method was used to optimize the following parameters: ethanol volume fraction in the extraction solvent, pod soaking time, liquid-solid ratio, microwave irradiation power, microwave irradiation time, and extraction cycles.

3.1.1. Effect of Ethanol Volume Fraction. Species and concentration of solvent is regarded as one of the most important parameters for MAE, which affects the solubility of the target component and the absorption of microwave energy [31, 32]. Although methanol has a great advantage in MAE for its best absorbance of the microwave energy, it is not recommended in food processing because of its toxicity [33]. So mixture 
of ethanol and water is recommended. In this study, the extractions were carried out with aqueous ethanol solutions at different concentrations (ethanol volume fraction from 0 to $90 \%)$ and with other conditions of $1 \mathrm{~h}$ soaking time, $10(\mathrm{~mL} / \mathrm{g})$ of liquid-solid ratio, $385 \mathrm{~W}$ of microwave irradiation power, $10 \mathrm{~min}$ of microwave irradiation time, and one extraction cycle.

Ethanol volume fraction significantly affected the extraction yields of luteolin and apigenin (Figure 2(a)). The extraction yield of luteolin significantly increased with the increase of ethanol volume fraction ranging from 0 to $50 \%$ and then decreased when ethanol volume fraction was higher than $80 \%$. It was found that the higher ethanol volume fraction was needed to extract apigenin than luteolin from the matrix, which was likely due to the smaller polarity of apigenin. The most efficient ethanol volume fractions for luteolin and apigenin were $50 \%$ and $70 \%$, respectively. Taking into account both of the total extraction yields and the economization on ethanol, $70 \%$ was considered for the optimal ethanol volume fraction.

3.1.2. Effect of Pod Soaking Time. Using of the technique of soaking can get better extraction efficiency of target compound in microwave-assisted processing [34]. Experiments were conducted to investigate the effect of soaking time on yields of luteolin and apigenin in MAE. Pod samples were soaked in $70 \%$ ethanol for $0,1,2,4$, or $8 \mathrm{~h}$. Then they were extracted in the microwave oven for $10 \mathrm{~min}$ at $385 \mathrm{~W}$. Information of the effect of soaking time on the extractions of luteolin and apigenin was given in Figure 2(b). A substantial increase in the extraction yield was obtained after soaking the pod. The target ingredients extraction yields increased significantly when the soaking time was $0-4 \mathrm{~h}(P<0.05)$; however longer soaking time did not lead to further increases in yield. Therefore, $4 \mathrm{~h}$ was chosen as the optimal soaking time.

3.1.3. Effect of Liquid-Solid Ratio. In an extraction process, it is important to maximize extraction yield but also to minimize the consumption of solvent. Inadequate solvent leads to low operational efficiency and excessive solvent leads to waste. For investigating the influence of liquid-solid ratio on extraction yields of luteolin and apigenin, tests were performed at different liquid-solid ratios ranging from 6 to $30(\mathrm{~mL} / \mathrm{g})$. The results showed that increasing liquid-solid ratio enhanced the extraction yields of luteolin and apigenin (Figure 2(c)), which was due to the increasing of driving force generated from the gradient concentration [35]. In the tested ratio ranging from 10 to 30 , no significant difference was found in extraction yields of luteolin and apigenin $(P>$ 0.05 ), which was due to the excessive swelling of the materials caused by the large volume of solvent, according to the reports of Yan et al. [33] and Ma et al. [36]. Hence, a value of 10 (mL/g) was considered the optimal liquid-solid ratio for the MAE process.

3.1.4. Effect of Microwave Irradiation Power. Microwave irradiation power is the other important factor affecting extraction yield of component in MAE. A higher microwave power increased the temperature of the mixture of the extraction solvent and sample, leading to higher mass transfer rates of substances from the sample [37]. In this study, the effect of irradiation power ranging from 120 to $700 \mathrm{~W}$ on extraction yields of luteolin and apigenin was investigated (Figure 2(d)). It was found that the extraction yields of luteolin and apigenin significantly increased when the microwave irradiation power increased from $120 \mathrm{~W}$ to $230 \mathrm{~W}(P<$ 0.05 ) and gradually decreased with the further increasing of irradiation power, which might be due to either thermal or oxidative degradation of luteolin and apigenin by the excessive irradiation. The results indicated that the optimum extraction condition was the use of the microwave power of $230 \mathrm{~W}$.

3.1.5. Effect of Microwave Irradiation Time. The influence of microwave irradiation time on the extraction yields of the luteolin and apigenin was examined over a range of 2-12 min; other factors were fixed at $70 \%$ ethanol volume fraction as extraction solvent, soaking time $4 \mathrm{~h}$, liquid-solid ratio $10(\mathrm{~mL} / \mathrm{g})$, microwave irradiation power $230 \mathrm{~W}$, and one extraction cycle. As shown in Figure 2(e), the extraction yields of luteolin and apigenin sharply increased with the increase of microwave irradiation time in the beginning of MAE. Luteolin and apigenin could reach their optimum extraction yields at $8 \mathrm{~min}$ during the extraction process. When microwave irradiation time was above $8 \mathrm{~min}$, no significant variation was found in extraction yields of luteolin and apigenin $(P>0.05)$. Thus, a microwave irradiation time of $8 \mathrm{~min}$ was chosen as the optimal microwave irradiation time.

3.1.6. Number of Extraction Cycles. Adequate extraction cycle contributes to the full extraction of interesting substances from the residue. The extraction yields of luteolin and apigenin were investigated in MAE process conducted 1-4 cycles, with other conditions of $70 \%$ ethanol volume fraction, $4 \mathrm{~h}$ of soaking time, $10(\mathrm{~mL} / \mathrm{g})$ of liquid-solid ratio, $230 \mathrm{~W}$ of microwave irradiation power, and $8 \mathrm{~min}$ of microwave irradiation time. The 2nd cycle significantly increased the yields of luteolin and apigenin $(P<0.05)$. It was the $3 \mathrm{rd}$ extraction cycle, but not the 4th cycle, that significantly enhanced the extraction yield of luteolin of MAE $(P<0.05)$ (Figure 2(f)). For saving solvent, energy, and time, threecycle extraction was sufficient to extract luteolin and apigenin present in tree peony pod.

3.2. Optimization Extraction Conditions by Response Surface Method (RSM). In order to study the most influential factors and the interactions between the factors, the liquid-solid ratio, microwave irradiation power, and time were optimized by RSM. In Table 1, the total extraction yield was defined as the sum of yields of luteolin and apigenin in an extraction experiment. The surface response analysis for the total extraction yield indicated that the effects of all the three factors on the response were significant with a positive linear relationship $(P<0.05)$. The empirical relationship between 


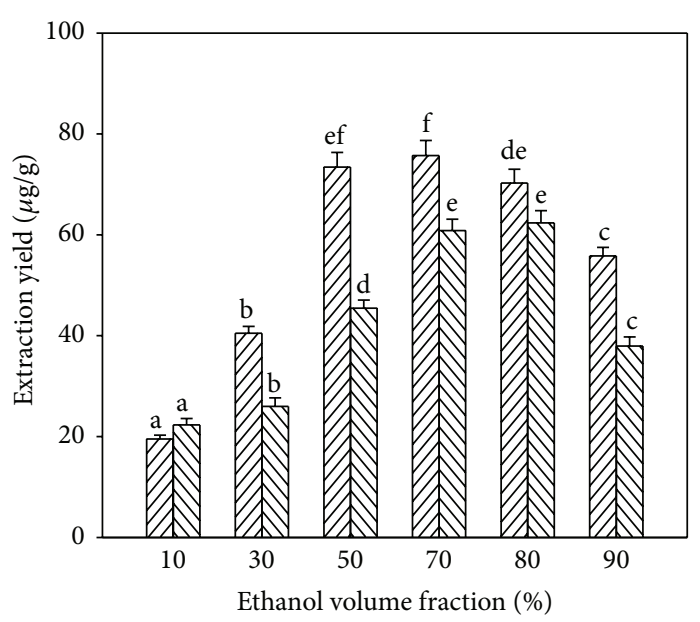

(a)

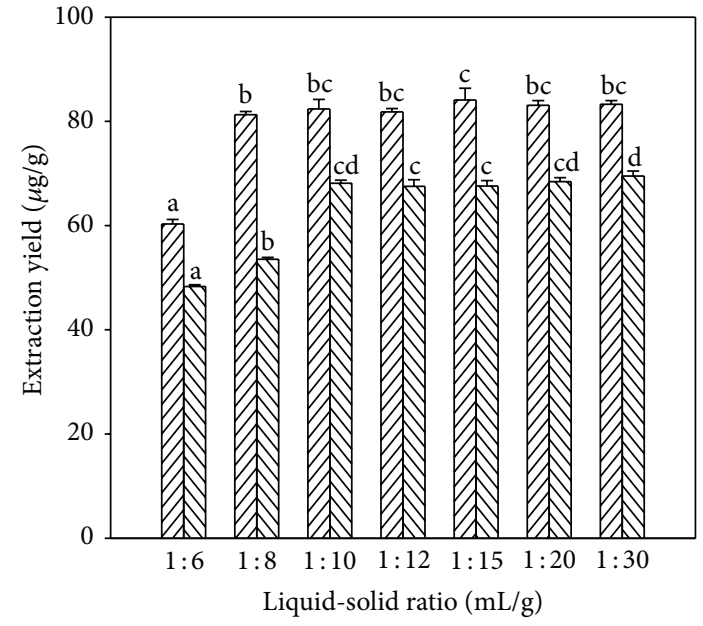

(c)

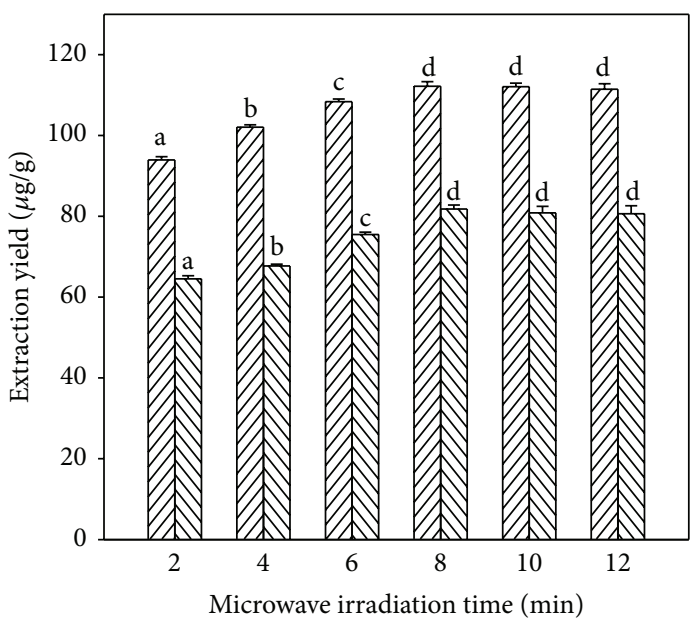

प7] Luteolin

$\triangle 1 \nabla$ Apigenin

(e)

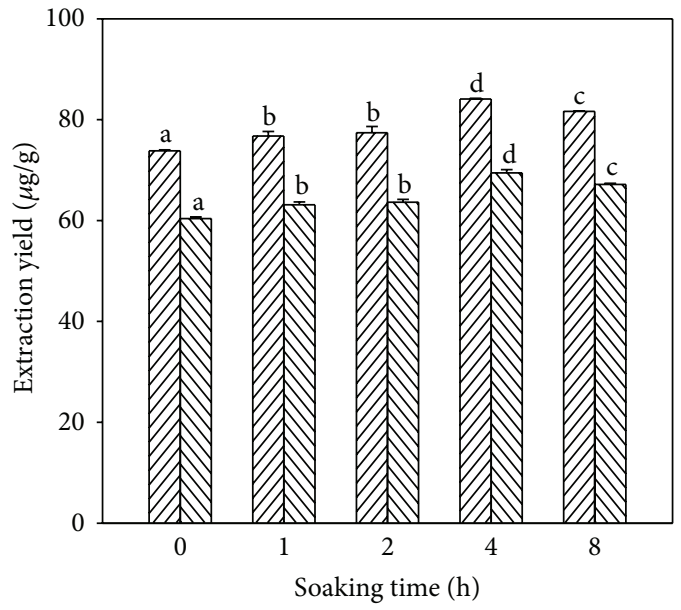

(b)

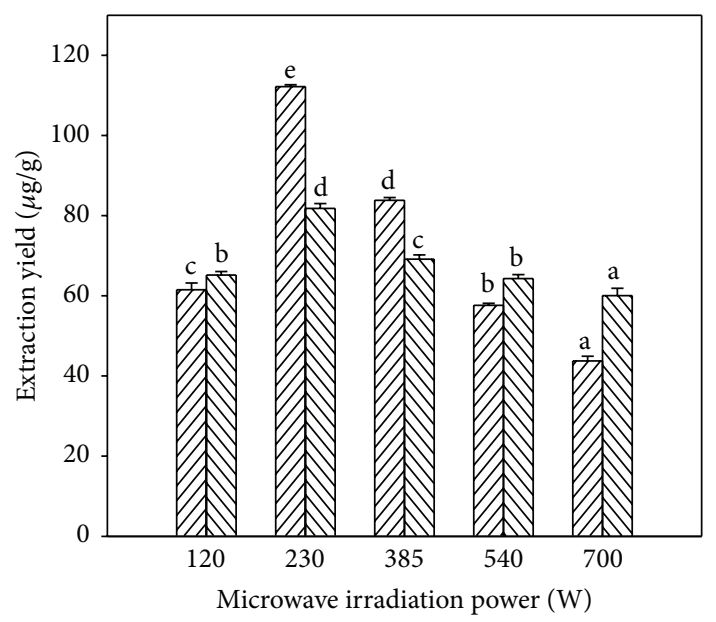

(d)

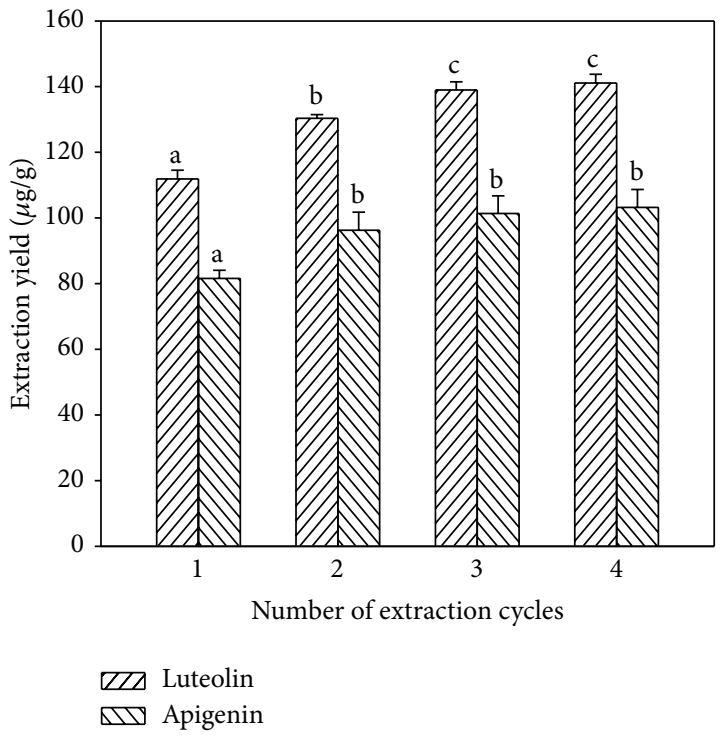

(f)

FIGURE 2: The influence conditions ((a): ethanol volume fraction; (b): soaking time; (c): liquid-solid ratio; (d): microwave irradiation power; (e): microwave irradiation time; (f): number of extraction cycles) on the extraction yields of luteolin and apigenin. The values represent means \pm standard deviation. Values followed by the same letter in the same assay are not significantly different $(P>0.05, n=3)$. 


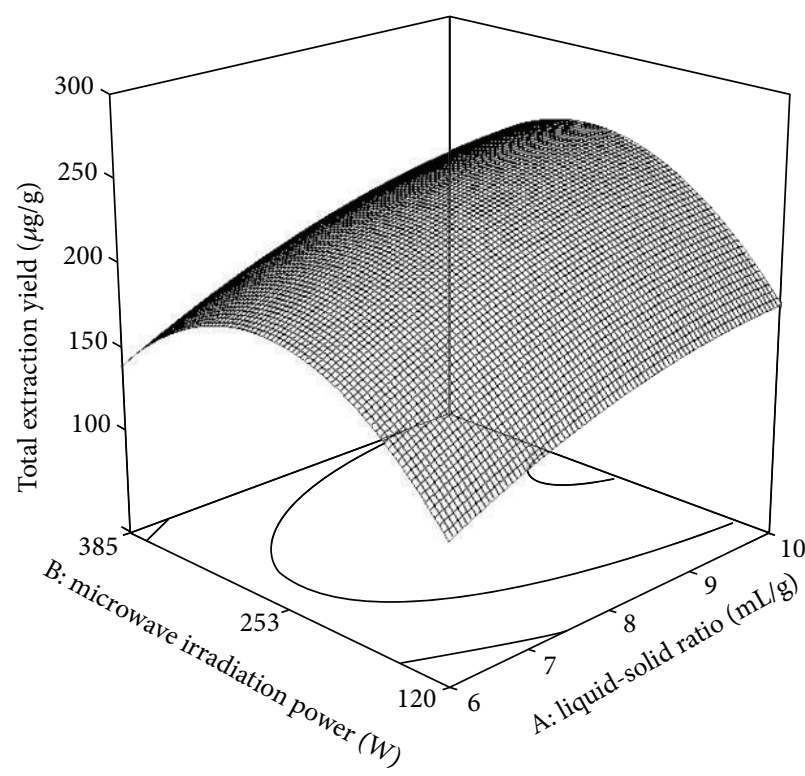

(a)

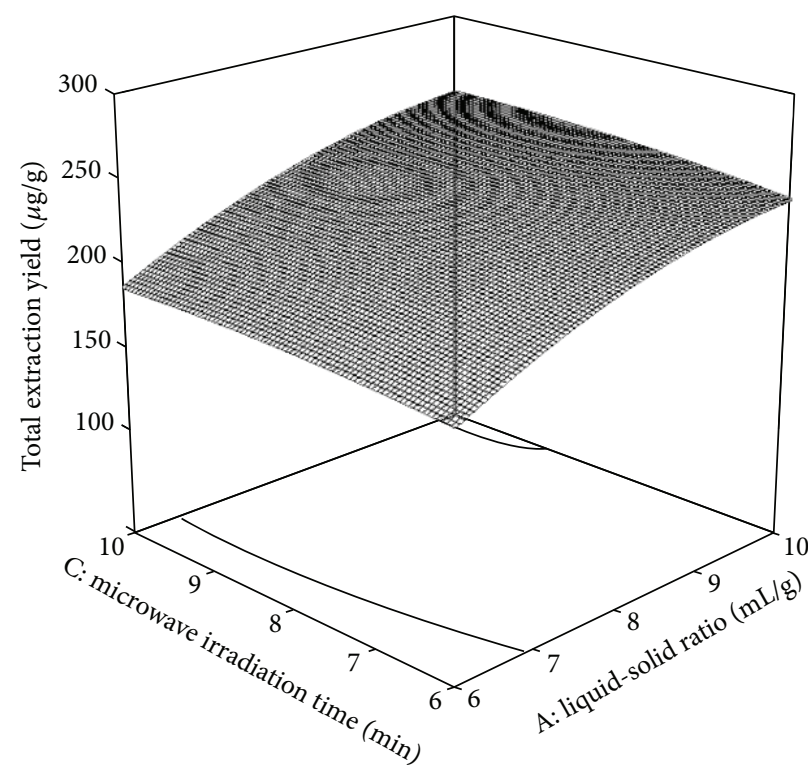

(b)

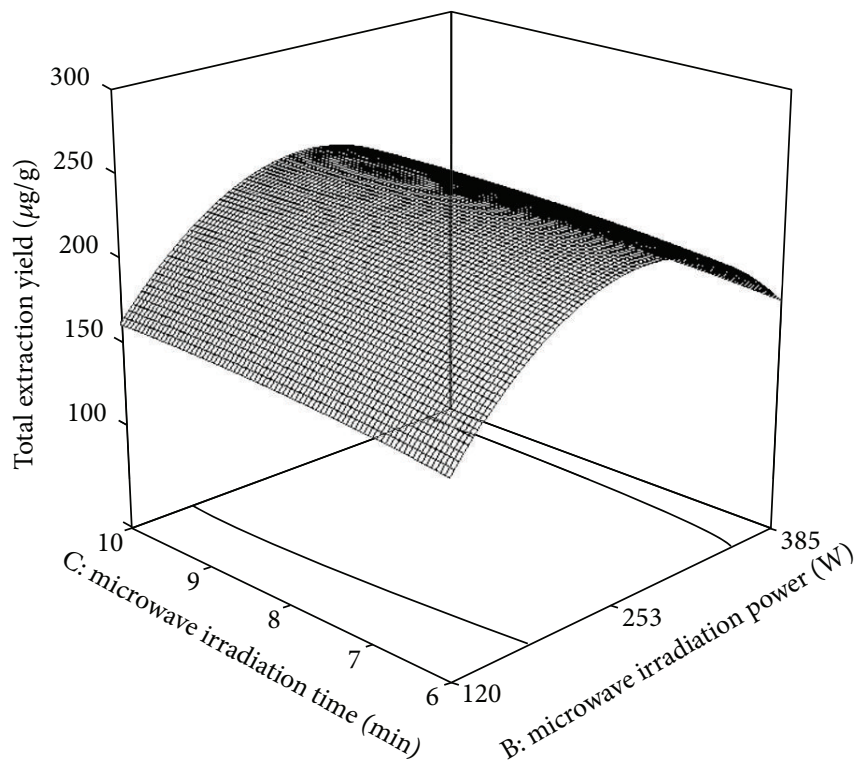

(c)

FIGURE 3: Response surface plots showing the effects of variables on total extraction yield. (a) Interaction of liquid-solid ratio and microwave irradiation power; (b) interaction of liquid-solid ratio and microwave irradiation time; (c) interaction of microwave irradiation power and time.

the total extraction yield and the extraction parameters was generated as follows:

$$
\begin{aligned}
Y= & -397.079+61.705 A+1.880 B+15.070 C+0.007 A B \\
& +0.250 A C-0.006 B C-3.125 A^{2}-0.004 B^{2}-0.875 C^{2} .
\end{aligned}
$$

It was found that there was no significance in the lack of fit $(P>0.05)$. The ANOVA analysis results showed that the quadratic model was valid for the spatial influence of variables on the response. Additionally, the $R^{2}$ value for the model was 0.996, which conformed with the fact that the model could adequately represent the true relationships between the three parameters. In this case, $A, B, C, A B, A^{2}$, $B^{2}$, and $C^{2}$ were the significant model terms. To highlight the interactions of the three factors on total extraction yield, 3D profiles of the model were illustrated in Figure 3, when the other parameters were kept constant.

The interaction of liquid-solid ratio and microwave irradiation power was shown in Figure 3(a). In these experiments, the other parameters were kept as follows: $70 \%$ ethanol volume fraction, $4 \mathrm{~h}$ of soaking time, $8 \mathrm{~min}$ of microwave 
irradiation time, and 3 extraction cycles. Increase of the microwave irradiation power from $120 \mathrm{~W}$ to $265.6 \mathrm{~W}$ with the liquid-solid ratio increasing from 6 to $10(\mathrm{~mL} / \mathrm{g})$ enhanced the total extraction yield. The further increase of the microwave irradiation power decreased the total extraction yield, likely due to the degradations of luteolin and apigenin under the high irradiation power. Additionally, denser contours were found along the axis of microwave irradiation power than along the axis of liquid-solid ration, indicating that microwave irradiation power had more influence on the total extraction yield than liquid-solid ratio.

Figure 3(b) represented the interaction of liquid-solid ratio and microwave irradiation time. In these experiments, the other parameters were kept as follows: $70 \%$ ethanol volume fraction, $4 \mathrm{~h}$ of soaking time, $230 \mathrm{~W}$ of microwave irradiation power, and 3 extraction cycles. A steady increase of total extraction yield was found when the liquid-solid ratio increased from 6 to $10(\mathrm{~mL} / \mathrm{g})$ along with the increase of the microwave irradiation time from 6 to $9.6 \mathrm{~min}$. A comparison of contour density along axis of liquid-solid ratio and microwave irradiation time suggested that the total extraction yield was more influenced by the liquid-solid ratio than microwave irradiation time.

The response surface for total extraction yield with various microwave irradiation powers and time was showed in Figure 3(c). In this case, the parameters of ethanol volume fraction, soaking time, liquid-solid ratio, and extraction cycles were fixed at $70 \%, 4 \mathrm{~h}, 10(\mathrm{~mL} / \mathrm{g})$, and 3 , respectively. Being the same as that found in Figure 3(a), the total extraction yield was elevated when the microwave irradiation power increased from 120 to $265.6 \mathrm{~W}$ along with the increase of microwave irradiation time from 6 to $9.6 \mathrm{~min}$. The denser contours along the axis of microwave irradiation power indicated that the parameter has a greater impact on the total extraction yield.

From the analysis of RSM, the optimal conditions of MAE can be summarized as follows: $70 \%$ ethanol volume fraction, $4 \mathrm{~h}$ soaking time, 10 (mL/g) of liquid-solid ratio, $265.6 \mathrm{~W}$ of microwave irradiation power, $9.6 \mathrm{~min}$ of microwave irradiation time, and 3 extraction cycles. Under these conditions, the total extraction yields can reach $256 \mu \mathrm{g} / \mathrm{g}$. Taking into account the feasibility in the actual operation, the parameter of microwave irradiation power was adjusted to $265 \mathrm{~W}$. To verify the model, MAE was done three times under these conditions. The actual total extraction yield was $255 \mu \mathrm{g} / \mathrm{g}$ with a deviation of $-0.39 \%$.

Under the conditions optimized by RSM, the extraction yields of luteolin and apigenin from tree peony pod were, respectively, $151 \mu \mathrm{g} / \mathrm{g}$ and $104 \mu \mathrm{g} / \mathrm{g}$. Luteolin and apigenin have also been reported in some other plant materials, such as S. grandifolra, C. cajan, and A. graveolens. The contents of luteolin and apigenin in them were, respectively, in range of about $20-550 \mu \mathrm{g} / \mathrm{g}$ and $40-730 \mu \mathrm{g} / \mathrm{g}$ [16-18]. The data indicated that the extract of tree peony pod would have favorable application value.

3.3. Comparison of MAE with Other Methods. The extraction yields of luteolin and apigenin from tree peony pod with
MAE, ME, and HRE were compared, and the results were shown in Table 2. The extraction yields of luteolin and apigenin were significantly higher with MAE than with HRE and ME $(P<0.05)$. The total extraction yield of MAE, HRE, and ME was 255, 220, and $145 \mu \mathrm{g} / \mathrm{g}$, respectively. The time of MAE with energy consumption was also shorter, with the HRE taking $120 \mathrm{~min}$ and the MAE only $24 \mathrm{~min}$. The comparison of MAE with ME showed that the microwave irradiation energy was important for increasing the extraction efficiency. MAE was an efficient method for the simultaneous extraction of luteolin and apigenin from tree peony pod.

\subsection{Evaluation of Antioxidant Activities}

3.4.1. DPPH Assay. In the present investigation, the DPPH assay was used to evaluate the radical-scavenging activity of tree peony pod extracts obtained by MAE, ME, and HRE, as well as of pure luteolin and apigenin. As shown in Figure 4(a), all extracts obtained by MAE, HRE, and ME possessed high scavenging activity of $\mathrm{DPPH}$ radical. The $\mathrm{IC}_{50}$ values of the three extracts were higher than that of the standard compound of luteolin and lower than apigenin. In the three extracts, the highest scavenging activity for $\mathrm{DPPH}$ radical was found in the extract obtained by MAE, suggesting that more compounds with hydrogen donating capabilities were extracted in MAE than in ME or HRE.

3.4.2. Ferric Reducing Antioxidant Power Assay. Antioxidant potential of the three extracts obtained by MAE, HRE, and ME was estimated from their abilities to reduce TPTZ-Fe (III) complex to TPTZ-Fe (II) complex, with pure luteolin and apigenin. Among all the samples, luteolin showed the highest FRAP $(10838 \mu \mathrm{mol} \mathrm{TE} / \mathrm{mg})$ and apigenin showed the lowest FRAP $(163 \mu \mathrm{mol} \mathrm{TE} / \mathrm{mg})$. Similar to the result in DPPH assay, MAE showed the pronounced effect on FRAP. The FRAP of extract obtained by MAE was higher than those obtained by HRE and ME, $20.0 \pm 1.4 \%$ and $36.9 \pm 3.3 \%$, respectively (Figure 4(b)).

3.4.3. Reducing Power Assay. The reducing powers of the extracts obtained by MAE, HRE, and ME were also tested in another system, in which the $\mathrm{Fe}^{3+}$ /ferricyanide complex transformed into its ferrous form. The amount of $\mathrm{Fe}^{2+} /$ ferricyanide complex was monitored by measuring the formation of Perl's Prussian blue at $707 \mathrm{~nm}$. Higher absorbance value indicated the higher reducing power [29, 38]. As shown in Figure 4(c), the reducing powers of all samples were concentration dependent ranging from $0.016 \mathrm{mg} / \mathrm{mL}$ to $0.25 \mathrm{mg} / \mathrm{mL}$, and good linear relationships were found between the samples concentration and the reducing powers. Agreeing with the DPPH and FRAP tests, the reducing powers of the crude extracts and the pure compounds were arranged as follow: luteolin $>$ MAE $>$ HRE $>\mathrm{ME}>$ apigenin.

From the results of DPPH, FRAP, and reducing power assay, it was obvious that MAE was beneficial for the extraction of the antioxidant substances. Polyphenols are the most abundant antioxidants in the plants and provide the main 


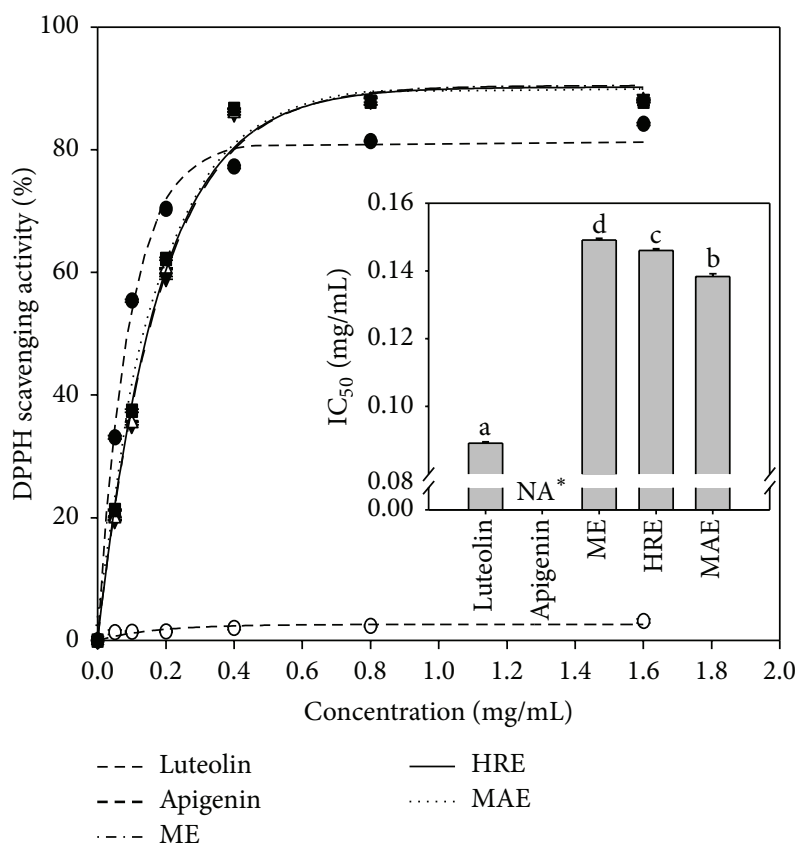

(a)

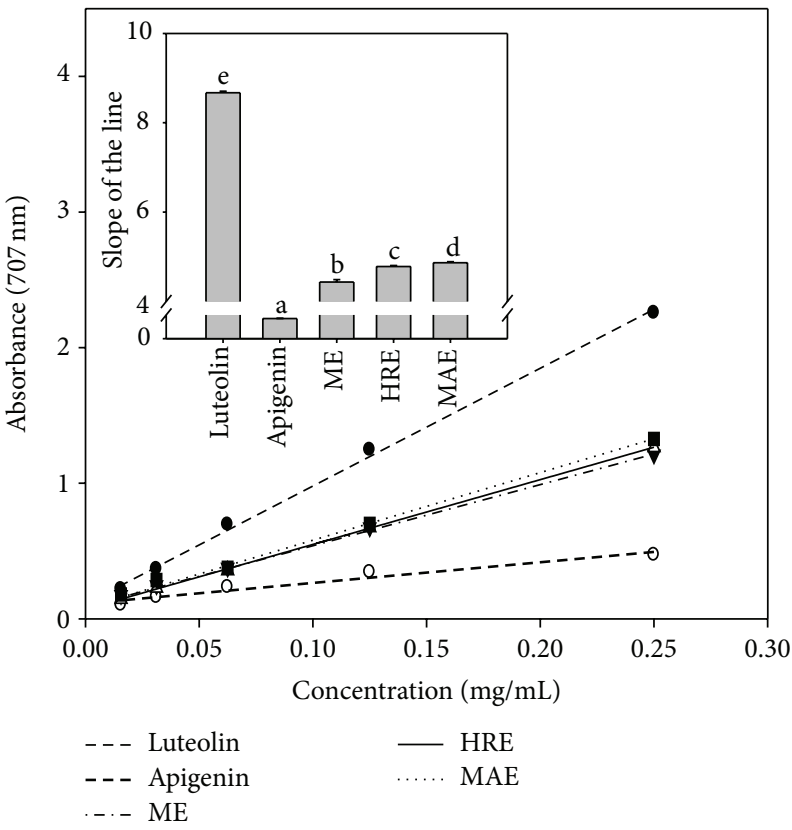

(c)

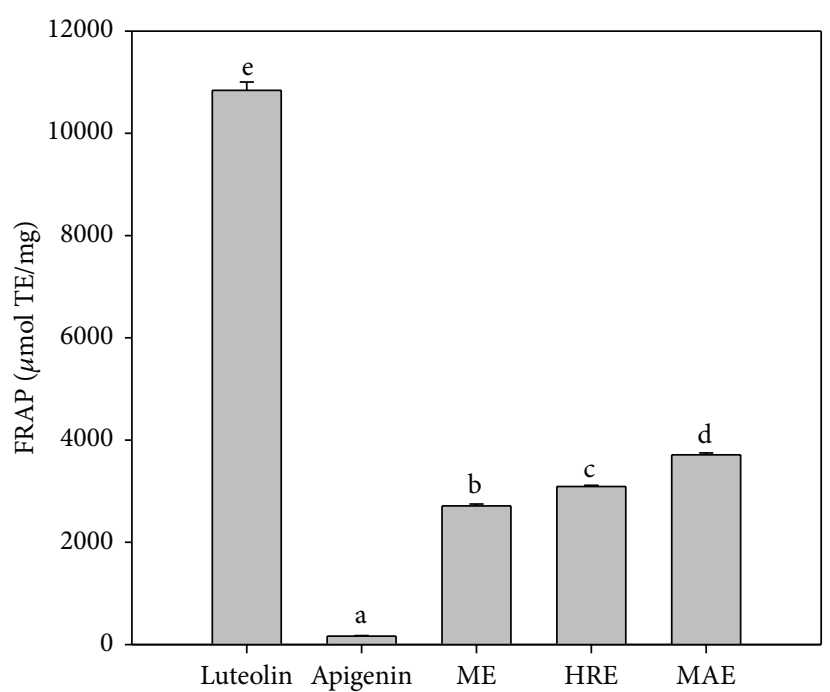

(b)

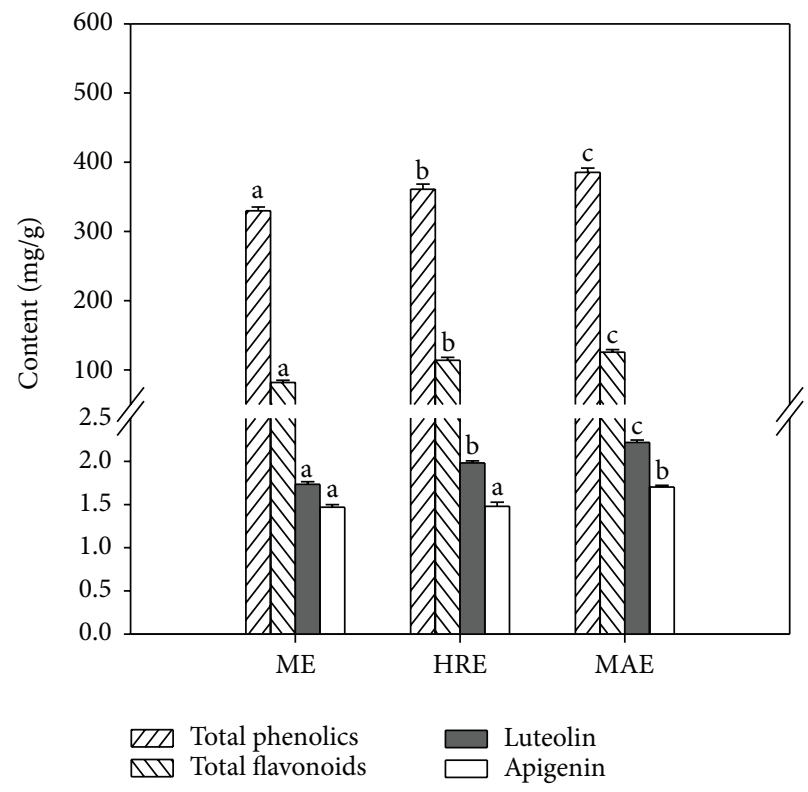

(d)

FIGURE 4: Antioxidant activity and antioxidants contents of crude extracts obtained by ME, HRE, and MAE of tree peony pod. (a) DPPH scavenging activity of the crude extracts; (b) FRAP of the crude extracts; (c) reducing power of the crude extracts; (d) total phenolics, total flavonoids, luteolin, and apigenin contents of the crude extracts. The values represent means \pm standard deviation. Values followed by the same letter in the same assay are not significantly different $(P>0.05, n=3)$. Note: $*$ means the value of $\mathrm{IC}_{50}$ cannot been obtained.

antioxidation in human diet [39]. In the three extracts, the highest contents of total phenolics and total flavonoids were found in the extract obtained by MAE (Figure 4(d)), which was in agreement with the results of antioxidant activities tests in vitro. In our study, antioxidant activities of luteolin were obviously higher than apigenin, which was consistent with the results in other studies [40-42]. The contents of luteolin and apigenin were also determined in the three extracts, and a positive relationship was found between the content of luteolin and antioxidative capacity of extract, but not the content of apigenin. It indicated that luteolin was an important antioxidant in the extract. 


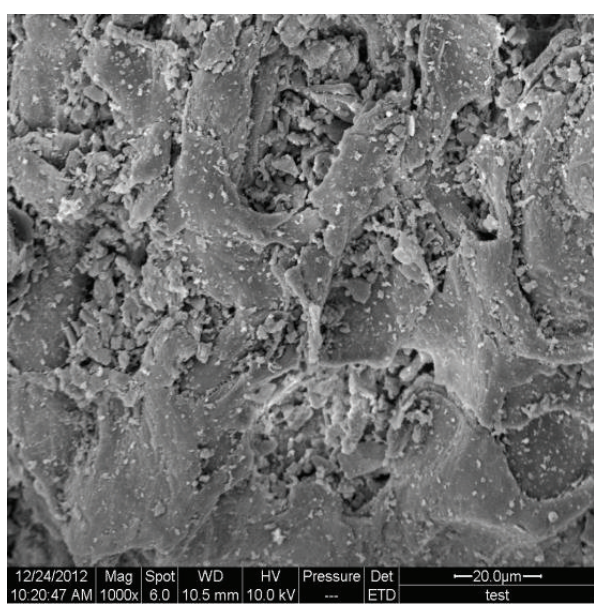

(a)

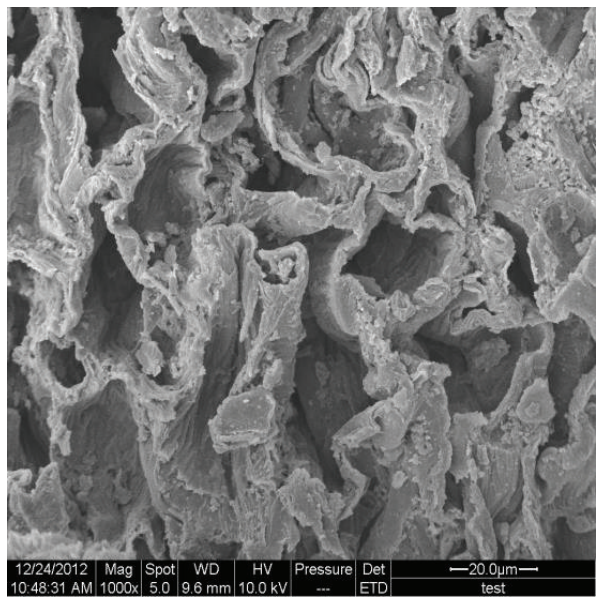

(c)

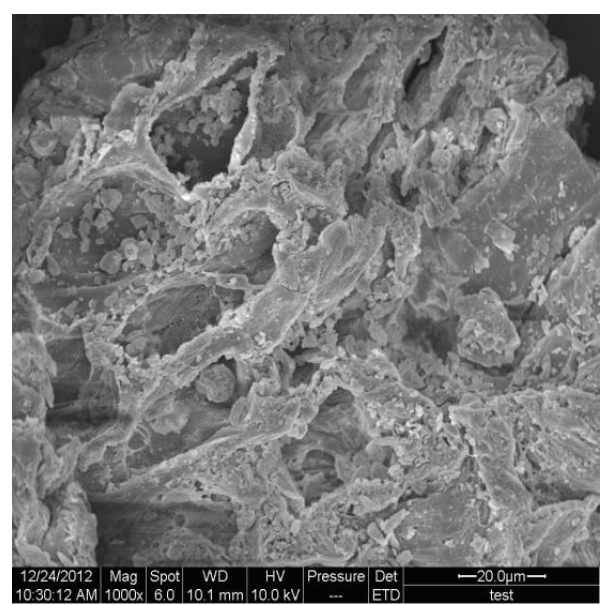

(b)

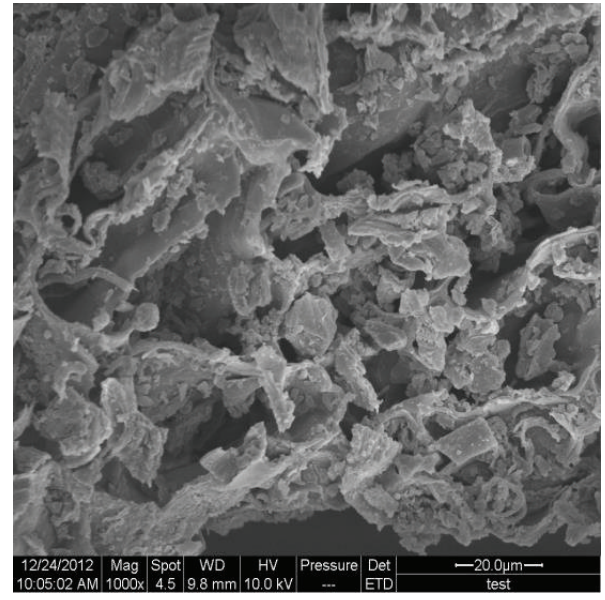

(d)

FIGURE 5: SEM images $(20.0 \mathrm{~lm}, 15.0 \mathrm{kV})$ of untreated tree peony pod sample (a), sample after ME (b), sample after HRE (c), and sample after MAE (d).

3.5. Structural Changes after Extraction. The various extraction methods produced different physical changes in tree peony pod. To investigate these physical changes during MAE, HRE, and ME, the pod samples were analyzed by SEM. Figure 5 displayed the micrographs of the pod samples before and after the different extraction methods. As shown in Figure 5(a), nubby parenchyma and nondestructed cell walls could be observed in the untreated raw material. No obvious change was found in sample with ME treatment compared to the untreated raw material, except for a few perforations (Figure 5(b)), which might be caused by the dissolution and denaturation of some compositions of cell wall. After HRE or MAE treatment, the sample became a crumbly texture (Figures 5(c) and 5(d)). However, a higher degree of damage was found in the sample with MAE treatment. MAE treatment induced clear wrinkle, dispersion, and fragmentation of external and internal cell walls of the particles, which might be due to the severe thermal stress and localized high pressure [43]. When the sample was subjected to irradiation, rapid heating of polar molecules in material and solvent led to the rapid expansion of the solvent volume, which built up a pressure within the cell. As a result of the continuous increase of the pressure, the structure of cell walls of sample particles was disrupted and that helped the rapid release of substances inside of the material particles to solvents [44].

\section{Conclusions}

In the present study, an efficient MAE method for simultaneous extraction of luteolin and apigenin from tree peony pod has been developed. The optimum conditions for MAE were studied using RSM. Under the optimized conditions, $151 \mu \mathrm{g} / \mathrm{g}$ luteolin and $104 \mu \mathrm{g} / \mathrm{g}$ apigenin were obtained. Compared to other methods, the proposed approach provides higher extraction yields and significantly reduced energy consumption time. Higher antioxidant activities were found in extract obtained by MAE than those obtained by HRE and $\mathrm{ME}$, being estimated in in vitro systems of $\mathrm{DPPH}$, TPTZ-Fe (III), and $\mathrm{Fe}^{3+} /$ ferricyanide complex. This indicated that more antioxidants were extracted from the pod using 
MAE. In these antioxidants, luteolin might be an important constituent responsible for the high antioxidant activities of the tree peony pod extracts. SEM results showed that MAE disintegrated the rigid wood material efficiently, increasing the release of secondary metabolites. The method may also prove to be useful in the development of efficient and energy saving extraction methods for other flavonoids.

\section{Conflict of Interests}

All the authors of this paper do not have any direct financial relation with the commercial identities mentioned in the paper that might lead to a conflict of interests regarding the publication of this paper.

\section{Acknowledgments}

This research was supported by the Fundamental Research Funds for the Central Universities (Grant no. 2572014CA09), the Special Fund for Forestry Scientific Research in the Public Interest (Grant no. 201404701), and the Program of Science and Technology from State Forestry Administration of China (Grant no. 2013-01).

\section{References}

[1] Chinese Pharmacopoeia Commission, Pharmacopoeia of the People's Republic of China, China Medical Science Press, Beijing, China, 2010.

[2] X. Wang, C. Cheng, Q. Sun, F. Li, J. Liu, and C. Zheng, "Isolation and purification of four flavonoid constituents from the flowers of Paeonia suffruticosa by high-speed counter-current chromatography," Journal of Chromatography A, vol. 1075, no. 1-2, pp. 127-131, 2005.

[3] C. Wang, P. Zhang, and Y. Dong, "The technique of the extraction of oil from peony seed with supercritical $\mathrm{CO}_{2}$ extraction method and the analysis of the composition," Journal of the Chinese Cereals and Oils Association, vol. 24, no. 8, pp. 96-99, 2009.

[4] J. Yi, W. Zhu, H. Ma, and Y. Wang, "Studies on chemical constituents from seeds of Paeonia suffruticosa Andr," Natural product Research and Development, vol. 21, no. 4, pp. 604-607, 2009.

[5] M. Madhesh and M. Vaiyapuri, "Effect of luteolin on lipid peroxidation and antioxidants in acute and chronic periods of isoproterenol induced myocardial infarction in rats," Journal of Acute Medicine, vol. 2, no. 3, pp. 70-76, 2012.

[6] X. Cai, T. Ye, C. Liu et al., "Luteolin induced G2 phase cell cycle arrest and apoptosis on non-small cell lung cancer cells," Toxicology in Vitro, vol. 25, no. 7, pp. 1385-1391, 2011.

[7] M. J. Wu, C. Y. Weng, H. Y. Ding, and P. J. Wu, "Antiinflammatory and antiviral effects of Glossogyne tenuifolia," Life Sciences, vol. 76, no. 10, pp. 1135-1146, 2005.

[8] J. Chang, Y. Hsu, P. Kuo, Y. Kuo, L. Chiang, and C. Lin, "Increase of Bax/ Bcl-XL ratio and arrest of cell cycle by luteolin in immortalized human hepatoma cell line," Life Sciences, vol. 76, no. 16, pp. 1883-1893, 2005.

[9] G. di Carlo, N. Mascolo, A. A. Izzo, and F. Capasso, "Flavonoids: old and new aspects of a class of natural therapeutic drugs," Life Sciences, vol. 65, no. 4, pp. 337-353, 1999.
[10] A. Zarzuelo, I. Jiménez, M. J. Gámez et al., "Effects of luteolin 5 -O- $\beta$-rutinoside in streptozotocin-induced diabetic rats," Life Sciences, vol. 58, no. 25, pp. 2311-2316, 1996.

[11] Y. T. Chen, R. L. Zheng, Z. J. Jia, and Y. Ju, "Flavonoids as superoxide scavengers and antioxidants," Free Radical Biology and Medicine, vol. 9, no. 1, pp. 19-21, 1990.

[12] K. Yamagata, C. Tagawa, H. Matsufuji, and M. Chino, "Dietary apigenin regulates high glucose and hypoxic reoxygenationinduced reductions in apelin expression in human endothelial cells," Journal of Nutritional Biochemistry, vol. 23, no. 8, pp. 929936, 2012.

[13] M. M. G. Pinheiro, F. Boylan, and P. D. Fernandes, "Antinociceptive effect of the Orbignya speciosa Mart. (Babassu) leaves: evidence for the involvement of apigenin," Life Sciences, vol. 91, no. 9-10, pp. 293-300, 2012.

[14] J. M. A. Patel, "Review of potential health benefits of flavonoids," Lethbridge Undergraduate Research Journal, vol. 3, no. 2, 2008.

[15] BBC Research, "Nutraceuticals : Global Markets and Processing Technologies," 2011, http://www.bccresearch.com/market-research/food-and-beverage/nutraceuticals-markets-processingtechnologies-fod013d.html.

[16] K. H. Miean and S. Mohamed, "Flavonoid (myricetin, quercetin, kaempferol, luteolin, and apigenin) content of edible tropical plants," Journal of Agricultural and Food Chemistry, vol. 49, no. 6, pp. 3106-3112, 2001.

[17] Y.-J. Fu, W. Liu, Y.-G. Zu et al., "Enzyme assisted extraction of luteolin and apigenin from pigeonpea [Cajanuscajan (L.) Millsp.] leaves," Food Chemistry, vol. 111, no. 2, pp. 508-512, 2008.

[18] D. Han and K. H. Row, "Determination of luteolin and apigenin in celery using ultrasonic-assisted extraction based on aqueous solution of ionic liquid coupled with HPLC quantification," Journal of the Science of Food and Agriculture, vol. 91, no. 15, pp. 2888-2892, 2011.

[19] S. W. Park, C. S. Cho, N. H. Ryu, J. H. Kim, and J. S. Kim, "Luteolin extracted from Platycodon grandiflorum protects retinal pigment epithelial cells from oxidative stress-induced caspase-3 dependent apoptosis," Biomedicine and Preventive Nutrition, vol. 2, no. 2, pp. 77-80, 2012.

[20] M. Bimakr, R. A. Rahman, F. S. Taip et al., "Comparison of different extraction methods for the extraction of major bioactive flavonoid compounds from spearmint (Mentha spicata L.) leaves," Food and Bioproducts Processing, vol. 89, no. 1, pp. 67-72, 2011.

[21] G. Zhao, G. W. Qin, J. Wang, W. J. Chu, and L. H. Guo, "Functional activation of monoamine transporters by luteolin and apigenin isolated from the fruit of Perilla frutescens (L.) Britt," Neurochemistry International, vol. 56, no. 1, pp. 168-176, 2010.

[22] X. Xiao, X. Si, X. Tong, and G. Li, "Preparation of flavonoids and diarylheptanoid from Alpinia katsumadai hayata by microwave-assisted extraction and high-speed counter-current chromatography," Separation and Purification Technology, vol. 81, no. 3, pp. 265-269, 2011.

[23] S.-Y. Wang, L. Yang, Y.-G. Zu et al., "Design and performance evaluation of ionic-liquids-based microwave-assisted environmentally friendly extraction technique for camptothecin and 10-hydroxycamptothecin from samara of camptotheca acuminata," Industrial \& Engineering Chemistry Research, vol. 50, no. 24, pp. 13620-13627, 2011.

[24] T. Liu, X. Sui, R. Zhang et al., "Application of ionic liquids based microwave-assisted simultaneous extraction of carnosic acid, 
rosmarinic acid and essential oil from Rosmarinus officinalis," Journal of Chromatography A, vol. 1218, no. 47, pp. 8480-8489, 2011.

[25] C.-H. Ma, T.-T. Liu, L. Yang et al., "Ionic liquid-based microwave-assisted extraction of essential oil and biphenyl cyclooctene lignans from Schisandra chinensis Baill fruits," Journal of Chromatography A, vol. 1218, no. 48, pp. 8573-8580, 2011.

[26] C.-H. Ma, L. Yang, Y.-G. Zu, and T.-T. Liu, "Optimization of conditions of solvent-free microwave extraction and study on antioxidant capacity of essential oil from Schisandra chinensis (Turcz.) Baill," Food Chemistry, vol. 134, no. 4, pp. 2532-2539, 2012.

[27] T. Guo, L. Wei, J. Sun, C.-L. Hou, and L. Fan, "Antioxidant activities of extract and fractions from Tuber indicum Cooke \& Massee," Food Chemistry, vol. 127, no. 4, pp. 1634-1640, 2011.

[28] L. Yang, J.-M. Huang, Y.-G. Zu et al., "Preparation and radical scavenging activities of polymeric procyanidins nanoparticles by a supercritical antisolvent (SAS) process," Food Chemistry, vol. 128, no. 4, pp. 1152-1159, 2011.

[29] S. Zu, L. Yang, J. Huang et al., "Micronization of taxifolin by supercritical antisolvent process and evaluation of radical scavenging activity," International Journal of Molecular Sciences, vol. 13, no. 7, pp. 8869-8881, 2012.

[30] X. Liu, J. Jia, L. Yang et al., "Evaluation of antioxidant activities of aqueous extracts and fractionation of different parts of Elsholtzia ciliata," Molecules, vol. 17, no. 5, pp. 5430-5441, 2012.

[31] L. Yang, X. Sun, F. Yang, C. Zhao, L. Zhang, and Y. Zu, "Application of ionic liquids in the microwave-assisted extraction of proanthocyanidins from Larix gmelini bark," International Journal of Molecular Sciences, vol. 13, no. 4, pp. 5163-5178, 2012.

[32] Y. Liu, L. Yang, Y. Zu et al., "Development of an ionic liquidbased microwave-assisted method for simultaneous extraction and distillation for determination of proanthocyanidins and essential oil in Cortex cinnamomi," Food Chemistry, vol. 135, no. 4, pp. 2514-2521, 2012.

[33] M.-M. Yan, W. Liu, Y.-J. Fu, Y.-G. Zu, C.-Y. Chen, and M. Luo, "Optimisation of the microwave-assisted extraction process for four main astragalosides in Radix Astragali," Food Chemistry, vol. 119, no. 4, pp. 1663-1670, 2010.

[34] F. Chen, K. Mo, Z. Liu et al., "Ionic liquid-based vacuum microwave-assisted extraction followed by macroporous resin enrichment for the separation of the three glycosides salicin, hyperin and rutin from Populus bark," Molecules, vol. 19, no. 7, pp. 9689-9711, 2014.

[35] F. Chen, K. Hou, S. Li, Y. Zu, and L. Yang, "Extraction and chromatographic determination of shikimic acid in Chinese conifer needles with 1-benzyl-3-methylimidazolium bromide ionic liquid aqueous solutions," Journal of Analytical Methods in Chemistry, vol. 2014, Article ID 256473, 12 pages, 2014.

[36] C. Ma, L. Yang, W. Wang, F. Yang, C. Zhao, and Y. Zu, "Extraction of dihydroquercetin from Larix gmelinii with ultrasoundassisted and microwave-assisted alternant digestion," International Journal of Molecular Sciences, vol. 13, no. 7, pp. 8789-8804, 2012.

[37] H. Yao, X. Du, L. Yang et al., "Microwave-assisted method for simultaneous extraction and hydrolysis for determination of flavonol glycosides in Ginkgo foliage using brönsted acidic ionic-liquid $\left[\mathrm{HO}_{3} \mathrm{~S}\left(\mathrm{CH}_{2}\right)_{4}\right.$ mim] $\mathrm{HSO}_{4}$ aqueous solutions," International Journal of Molecular Sciences, vol. 13, no. 7, pp. 8775-8788, 2012.
[38] Z. Liu, C. Ma, L. Yang, and Y. Zu, "Process optimization of ultrasonic-assisted extraction of arabinogalactan from dihydroquercetin extracted residues by response surface methodology and evaluation of its antioxidant activity," Journal of Chemistry, vol. 2013, Article ID 346810, 9 pages, 2013.

[39] Q. Lu, W. Liu, L. Yang et al., "Investigation of the effects of different organosolv pulping methods on antioxidant capacity and extraction efficiency of lignin," Food Chemistry, vol. 131, no. 1, pp. 313-317, 2012.

[40] I. M. C. Brighente, M. Dias, L. G. Verdi, and M. G. Pizzolatti, "Antioxidant activity and total phenolic content of some Brazilian species," Pharmaceutical Biology, vol. 45, no. 2, pp. 156-161, 2007.

[41] M. Majewska, M. Skrzycki, M. Podsiad, and H. Czeczot, "Evaluation of antioxidant potential of flavonoids: an in vitro study," Acta Poloniae Pharmaceutica: Drug Research, vol. 68, no. 4, pp. 611-615, 2011.

[42] T. Yi, Q. Chen, X. He et al., "Chemical quantification and antioxidant assay of four active components in Ficus hirta root using UPLC-PAD-MS fingerprinting combined with cluster analysis," Chemistry Central Journal, vol. 7, no. 1, article 115, 2013.

[43] M.-T. Golmakani and K. Rezaei, "Comparison of microwaveassisted hydrodistillation withthe traditional hydrodistillation method in the extractionof essential oils from Thymus vulgaris L," Food Chemistry, vol. 109, no. 4, pp. 925-930, 2008.

[44] Y. Kong, Y.-G. Zu, Y.-J. Fu et al., "Optimization of microwaveassisted extraction of cajaninstilbene acid and pinostrobin from pigeonpea leaves followed by RP-HPLC-DAD determination," Journal of Food Composition and Analysis, vol. 23, no. 4, pp. 382$388,2010$. 

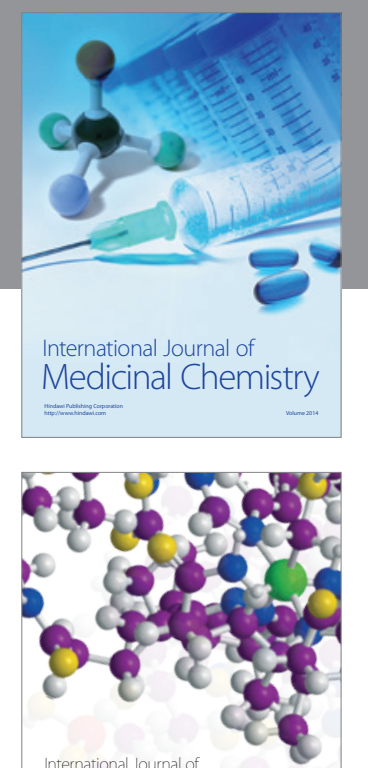

\section{Carbohydrate} Chemistry

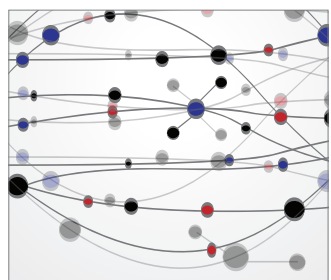

The Scientific World Journal
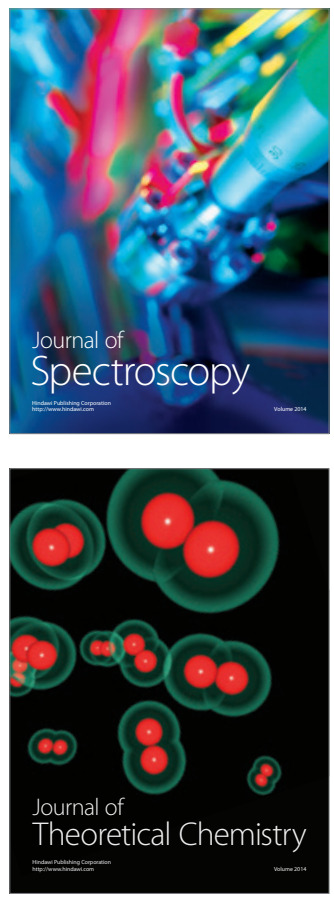
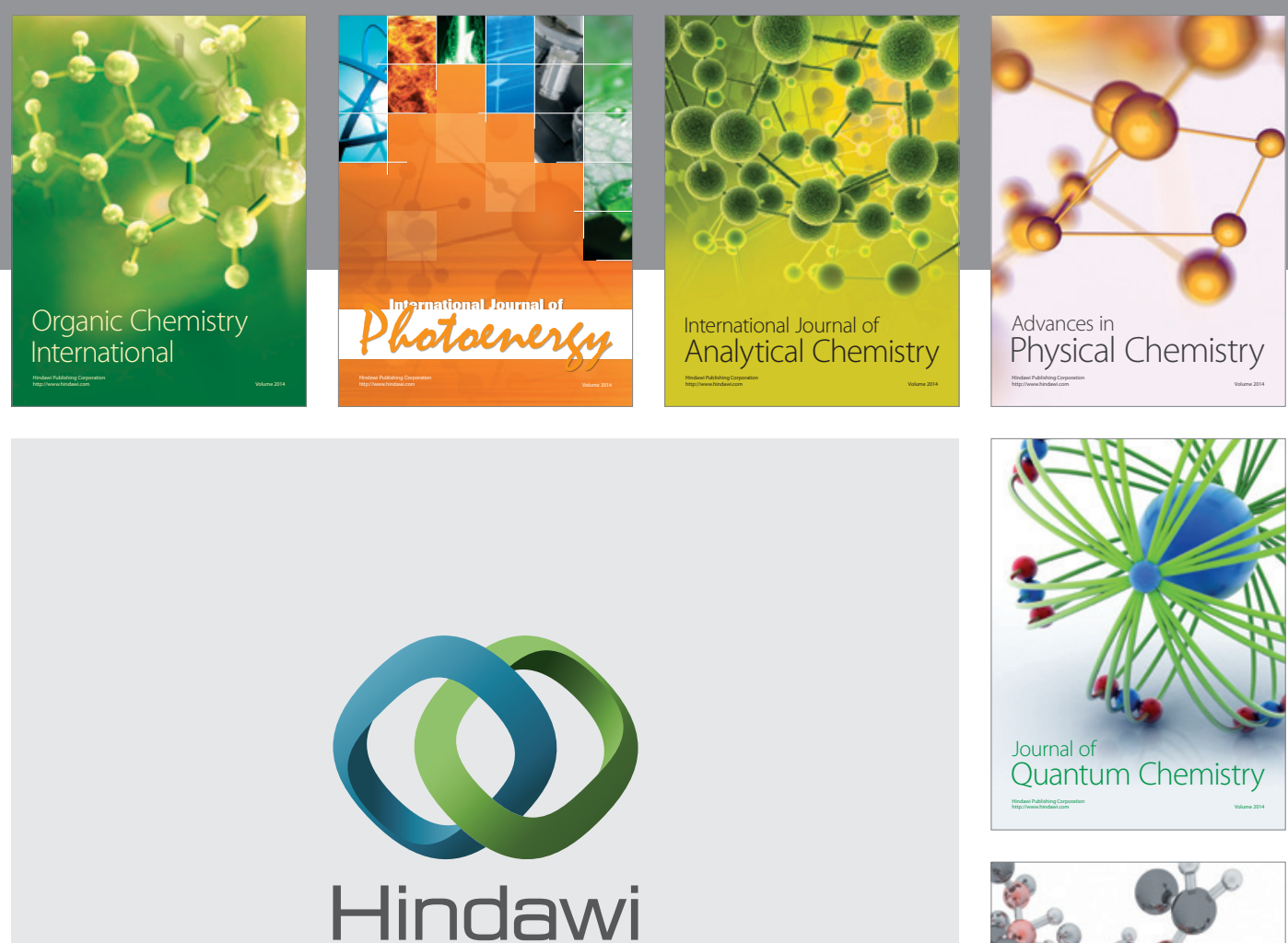

Submit your manuscripts at

http://www.hindawi.com

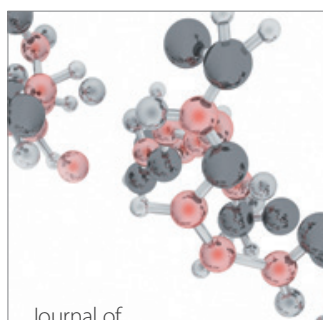

Analytical Methods

in Chemistry

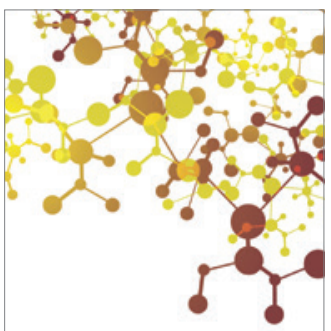

Journal of

Applied Chemistry

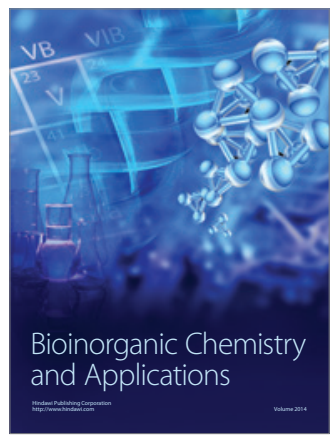

Inorganic Chemistry
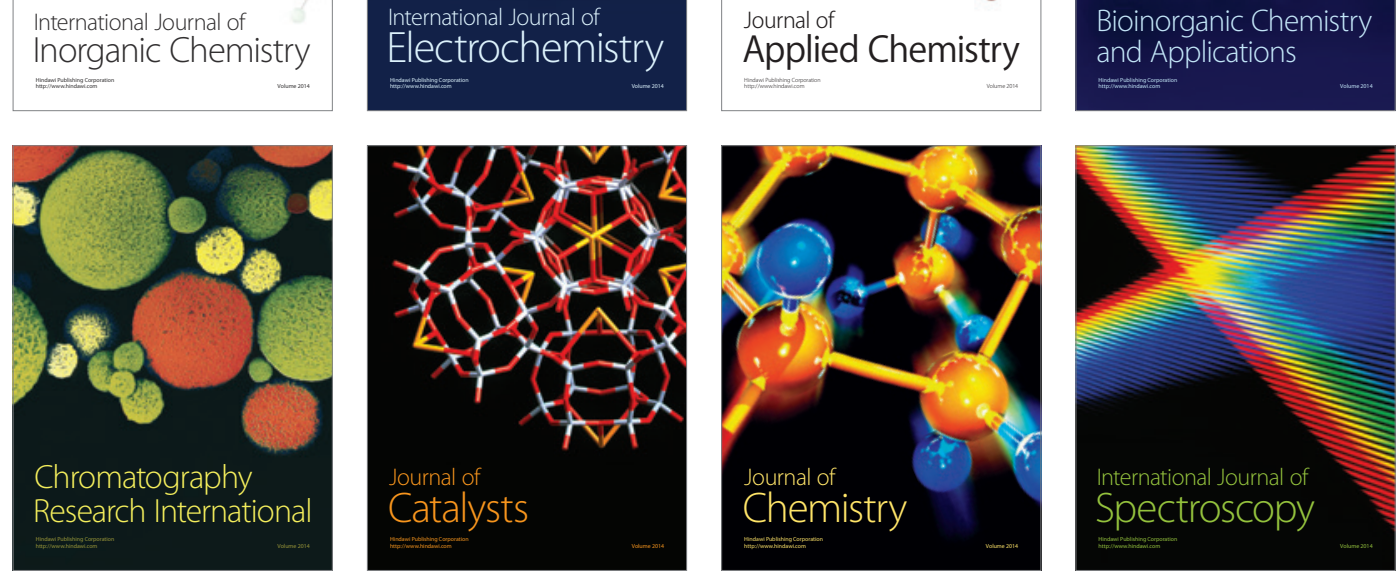